\title{
Isolated myeloid sarcoma presenting with small bowel obstruction: a case report
}

\author{
Rie Mizumoto ${ }^{1}$, Masanori Tsujie", Tomoko Wakasa², Kotaro Kitani', Hironobu Manabe', Shuichi Fukuda', \\ Kaoru Okada', Shumpei Satoi ${ }^{1}$, Hajime Ishikawa' ${ }^{1}$, Toshihiko Kawasaki ${ }^{3}$, Hitoshi Hanamoto ${ }^{4}$, Masao Yukawa ${ }^{1 *}$ and \\ Masatoshi Inoue ${ }^{1}$
}

\begin{abstract}
Background: Myeloid sarcoma (MS) is a solid tumor consisting of myeloid blasts or immature myeloid cells, which are unusual outside the bone marrow.

Case presentation: We present a rare case of isolated myeloid sarcoma of the small bowel in a 54-year-old man who was admitted to our hospital with repeated symptoms of intestinal obstruction. A small bowel series via an ileus tube revealed severe jejunal obstruction. Computed tomography revealed that the obstruction was likely caused by a jejunal tumor. The patient underwent laparoscopy-assisted partial resection of the jejunum with lymphadenectomy. Histopathological examination of the surgical specimen confirmed that MS had been responsible for the obstruction.

Conclusions: Patients with MS require systemic chemotherapy, as do patients with acute myeloid leukemia. Hence, an early, accurate diagnosis is imperative for treating this malignancy. It is also important to list MS in the differential diagnosis of a small bowel tumor, even in nonleukemic patients.
\end{abstract}

Keywords: Myeloid sarcoma, Intestine, Chemotherapy

\section{Background}

Myeloid sarcoma (MS), a solid tumor consisting of myeloid blasts or immature myeloid cells outside the bone marrow, is an unusual presentation of acute myeloid leukemia (AML). MS is also known by other names-e.g., chloroma, granulocytic sarcoma-which can create some confusion in understanding this disease. MS can develop anywhere in the body, with the most common sites being the lymph nodes, bone/ spine, and skin. Development of MS in the small intestine is reported to account for $10-11 \%$ of all MSs occurring in the gastrointestinal tract [1]. Because of its rarity and difficult diagnosis, MS has often been misdiagnosed as other diseases [2]. Here, we report a rare case of isolated primary MS of the small bowel causing intestinal obstruction.

\footnotetext{
* Correspondence: myukawa@med.kindai.ac.jp

${ }^{1}$ Department of Surgery, Kindai University Nara Hospital, 1248-1 Otoda,

Ikoma, Nara 630-0293, Japan

Full list of author information is available at the end of the article
}

\section{Case presentation}

A 54-year-old man with a history of hypertension and hyperlipidemia was admitted to our hospital complaining of abdominal pain and vomiting. He showed abdominal bloating but no signs of peritoneal irritation. Contrastenhanced computed tomography (CT) revealed local thickening of the small bowel wall, which was assumed to be due to an inflammatory reaction (Fig. 1). We diagnosed inflammatory disease, administered conservative treatment, which was effective, and did not perform further checkups. After resuming oral intake, he was discharged 10 days after admission. A few days after discharge, however, his abdominal symptoms recurred, and he was readmitted to our hospital.

Blood tests showed a mild inflammatory reaction and dehydration. The white blood cell count was $8200 / \mu \mathrm{l}$, with $62.3 \%$ neutrophils, $28.3 \%$ lymphocytes, $0.7 \%$ eosinophils, $0.5 \%$ basophils, and $8.3 \%$ monocytes. Other laboratory tests showed the following: hemoglobin $14.5 \mathrm{~g} / \mathrm{dl}$, platelets $265,000 / \mu \mathrm{l}$, CEA $7.5 \mathrm{ng} / \mathrm{ml}$, CA19-9 $4.5 \mathrm{U} / \mathrm{ml}$, and sIL-2R $313 \mathrm{U} / \mathrm{ml}$. After insertion of an ileus tube, a 


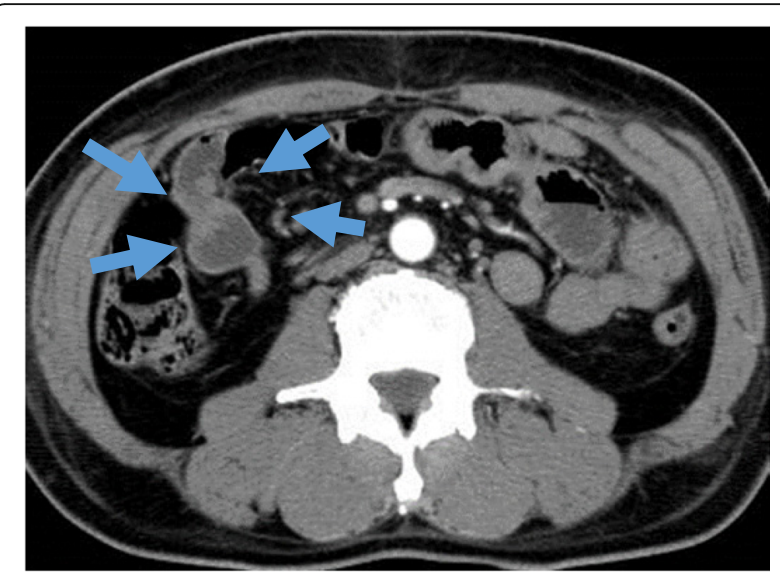

A

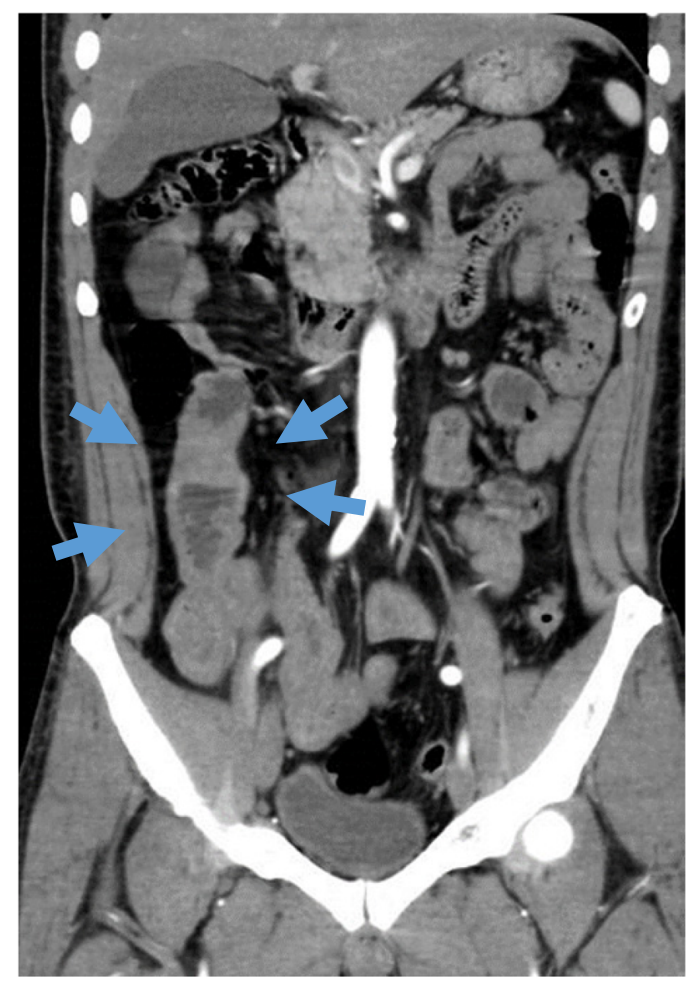

B

Fig. 1 Contrast-enhanced abdominal computed tomography shows thickening of the small bowel wall. a Axial view. b Coronal view

small bowel series revealed severe obstruction in the jejunum with upstream dilatation (Fig. 2). CT showed that thickening of the jejunal wall was still causing obstruction. Because of the results of those assessments, we performed a laparoscopic exploratory examination for a more accurate diagnosis. The laparoscopic views revealed a hard mass at the stenotic site, prompting us to perform small bowel resection with mesenteric lymph node dissection in consideration that the tumor might be malignant. The surgical view showed a palpable, elastic, hard mass in the jejunum, necessitating partial

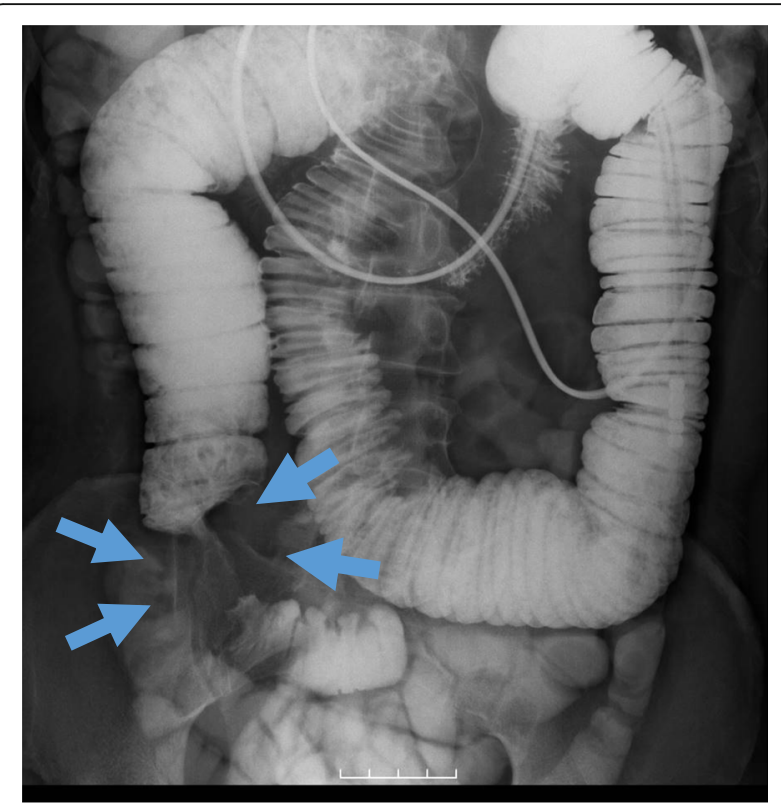

Fig. 2 Small bowel series via the ileus tube shows severe obstruction in the jejunum with upstream dilatation

resection of the jejunum with $10-\mathrm{cm}$ margins from the tumor on both sides and mesenteric lymphadenectomy. During the lymph node dissection of the small intestinal mesentery, we removed seven lymph nodes, none of which showed signs of metastasis.

Macroscopic examination of the resected specimen revealed a tumor approximately $60 \mathrm{~mm}$ in diameter that had caused stenosis of the entire jejunal circumference (Fig. 3). Histologically, hematoxylin and eosin (HE) staining showed diffuse infiltration and expansion of immature, atypical cells but without tissue destruction (Fig. 4). Immunochemical staining revealed that the cells were positive for myeloperoxidase (MPO) and CD34 and negative

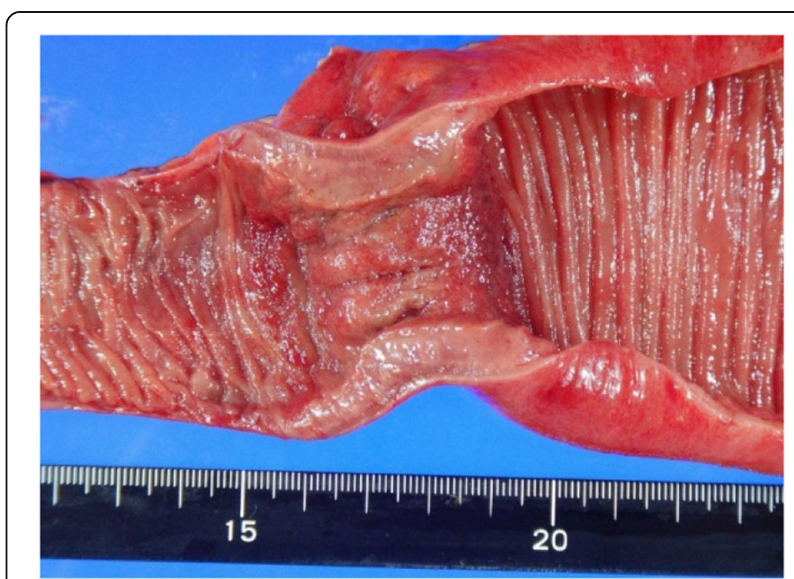

Fig. 3 Resected mass measured approximately $60 \times 50 \mathrm{~mm}$. The mass, which was elastic and hard, blocked the entire circumference of the elevated cut surface 

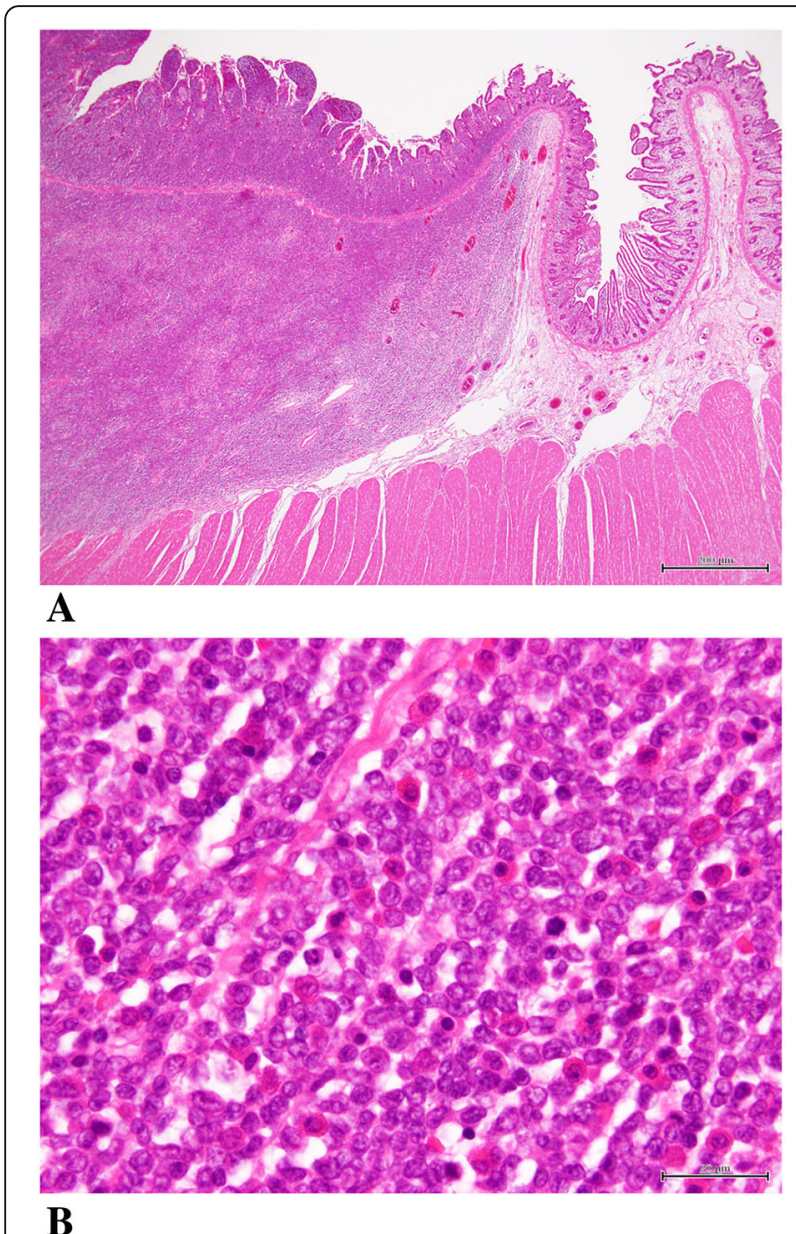

Fig. 4 Small intestine specimen shows diffuse infiltration and expansion of immature, atypical cells without tissue destruction (HE; $\mathbf{a} \times 20, \mathbf{b} \times 200)$

for CD20 (L26), CD3, CD30 (Ki1), CK (AE1/AE3), CK (MNF116), desmin, CD56, HMB-45, and S-100-protein (Fig. 5). These results confirmed the diagnosis of isolated jejunal MS. The patient's postoperative recovery was uneventful, and he was discharged from the hospital 9 days after the surgery.

Although the bone marrow aspiration evaluation was negative for cytological findings of leukemia, and ${ }^{18} \mathrm{~F}$-fluorodeoxyglucose-positron emission tomography (FDG-PET) showed no abnormal uptake, the patient was started on systemic chemotherapy for AML 6 months after his surgery.

\section{Discussion}

MS occurs as an initial or replacement presentation of AML and sometimes as a complication of myeloproliferative disorders. Isolated MS is rare, with only $1.4-9.0 \%$ of AML patients reported to develop MS [3]. Kitagawa et al. reported that the interval between the diagnosis of MS and the occurrence of AML varied from 0.5 to 24 months in patients with initial MS [2]. The male/female

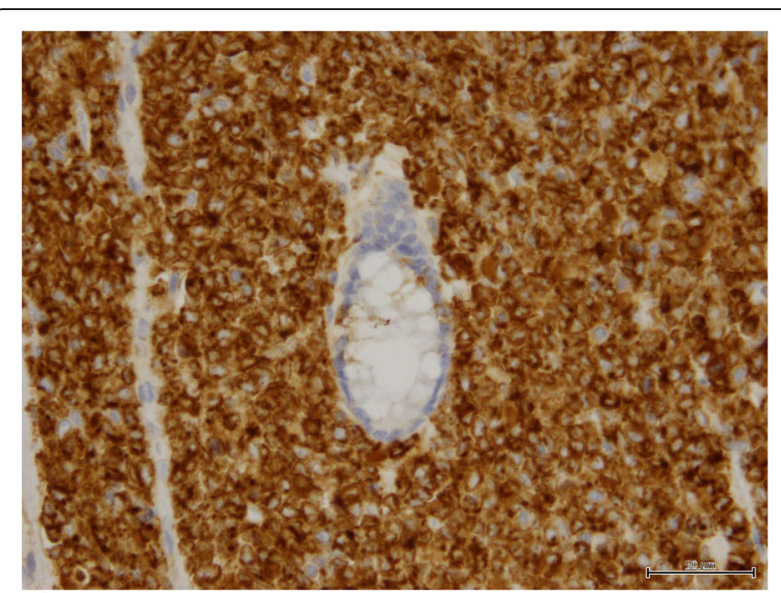

\section{A}

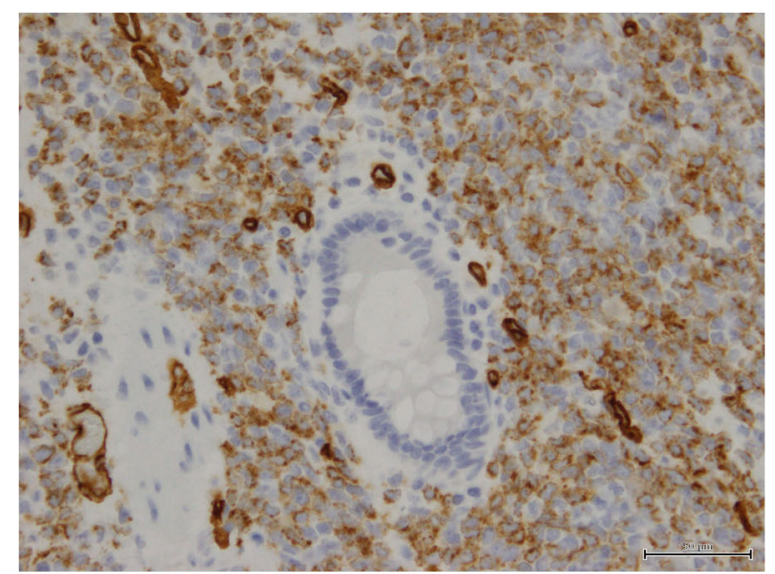

B

Fig. $\mathbf{5}$ Immunohistochemistry shows staining of the tumor cells for myeloperoxidase (MPO) (a) and CD34 (b)

ratio is 1.2:1, and the median age was 56 years (range 1 month to 89 years) [4].

Imaging and biopsy results are useful for confirming the diagnosis. FDG-PET shows high uptake by the tumor, and pathological examination shows both diffuse and concentrated areas of hyperplasia with large oval cells $[1,5]$. It has been reported, however, that almost half the patients with MS have been misdiagnosed as having a primary or metastatic malignant tumor, especially malignant lymphoma $[2,6]$. We did not list MS in the differential diagnosis of the patient and thus arrived at a misdiagnosis. Immunohistochemical examinations (e.g., CD68/KP1, CD33, CD34, CD117, and MPO) are performed to characterize the MS [4]. In our case, MPO was useful for establishing an accurate diagnosis.

Surgical resection is performed to treat an intestinal obstruction, as in our case, but MS patients should be treated with systemic chemotherapy tailored to the AML. Yamauchi and Yasuda analyzed 74 clinical records and showed that the median interval from MS to acute non-lymphocytic leukemia was significantly shorter 





among the patients who underwent surgical resection with or without irradiation than in those treated with chemotherapy only [6].

MS is rarely seen in the small intestine and certainly would not be easily recognized by general surgeons. Moreover, there is some confusion about the terminology. MS is described as a granulocytic sarcoma (extramedullary myelogenous leukemia) in Diagnostic Surgical Pathology, 3rd Edition published in 1999 and as a granulocytic sarcoma or a chloroma in Surgical Pathology, 10th Edition published in 2011 [7, 8]. Furthermore, it is called a myeloid sarcoma, granulocytic sarcoma, and chloroma in Surgical Pathology, 11th Edition published in 2018 [9]. MS is not even listed In WHO Classification of Tumours of the Digestive System, 4th Edition [10]. Hence, it appears desirable that, in the future, the definition of MS be unified regarding terminology.

In most cases of intestinal MS, patients exhibit symptoms of bowel obstruction. A review of the English-language literature between 2002 and 2019 revealed 18 cases of nonleukemic MS of the small intestine (Table 1). Although the type of treatment was not described in 2 cases, the remaining 16 patients underwent surgical resection. Among these 18 patients, 12 were treated with chemotherapy for AML, all of whom experienced complete remission. Among the remaining 6 patients, 4 were treated with surgery only, and 2 of the 4 developed AML. It is important for patients with MS to have an early, accurate diagnosis and to start treatment for AML as soon as possible.

\section{Conclusion}

We report the case of an isolated MS that presented with small bowel obstruction. MS is not well known, and many patients with the disease have been assigned an incorrect diagnosis at their first evaluation. Although it is difficult to confirm the diagnosis-especially when MS precedes the occurrence of AML-it is imperative for MS patients to have an early, definitive diagnosis and to start treatment for AML as rapidly as possible. Therefore, we must cite MS as one of the differential diagnoses of small bowel tumors, even in patients without any symptoms of leukemia.

\section{Abbreviations}

MS: Myeloid sarcoma; AML: Acute myeloid leukemia; CT: Computed tomography; HE: Hematoxylin-eosin; MPO: Myeloperoxidase; FDG-PET: ${ }^{18}$ Ffluorodeoxyglucose-positron emission tomography

\section{Acknowledgements}

We thank Nancy Schatken, BS, MT (ASCP), from Edanz Group (www. edanzediting.com/ac), for editing a draft of this manuscript.

\section{Authors' contributions}

RM, KK, HM, TW, SF, KO, SS, MT, GI, TK, MY, and Ml participated in the treatment of this patient and wrote the draft of the manuscript. All authors read and approved the final manuscript.

\section{Funding}

None

Ethics approval and consent to participate

Not applicable

\section{Consent for publication}

Written informed consent was obtained from the patient's next of kin to publish this case report and any accompanying images.

\section{Competing interests}

The authors declare that they have no competing interests.

\section{Author details}

${ }^{1}$ Department of Surgery, Kindai University Nara Hospital, 1248-1 Otoda, Ikoma, Nara 630-0293, Japan. ²Department of Pathology and Laboratory Medicine, Kindai University Nara Hospital, 1248-1 Otoda, Ikoma, Nara 630-0293, Japan. ${ }^{3}$ Department of Gastroenterology and Hepatology, Kindai University Nara Hospital, 1248-1 Otoda, Ikoma, Nara 630-0293, Japan. ${ }^{4}$ Department of Hematology, Kindai University Nara Hospital, 1248-1 Otoda, Ikoma, Nara 630-0293, Japan.

Received: 2 August 2019 Accepted: 6 December 2019

Published online: 03 January 2020

\section{References}

1. Kohl SK, Aoun P. Granulocytic sarcoma of the small intestine. Arch Pathol Lab Med. 2006:130:1570-4.

2. Kitagawa Y, Sameshima Y, Shiozaki H, Ogawa S, Masuda A, Mori SI, et al. Isolated granulocytic sarcoma of the small intestine successfully treated with chemotherapy and bone marrow transplantation. Int J Hematol. 2008; 87:410-3.

3. Alexiev BA, Wang W, Ning Y, Chumsri S, Gojo I, Rodgers WH, et al. Myeloid sarcomas: a histologic, immunohistochemical, and cytogenetic study. Diagn Pathol. 2007:31:2-42.

4. Pileri SA, Orazi A, Falini B. Myeloid sarcoma. In: Swerdlow SH, Campo E, Harris NL, Jaffe ES, Pileri SA, Stein $\mathrm{H}$, et al, editors. WHO classification of tumours of haematopoietic and lymphoid tissues. 4th ed. International Agency for Research on Cancer Lyon; 2008. p. 140-1

5. Chandra P, Dhake S, Purandare N, Agrawal A, Shah S, Rangarajan V. Role of FDG PET/CT in diagnostic evaluation of granulocytic sarcomas: a series of 12 patients. Indian J Nucl Med. 2017;32:198-202.

6. Yamauchi K, Yasuda M. Comparison in treatments of nonleukemic granulocytic sarcoma: report of two cases and a review of 72 cases in the literature. Cancer. 2002;94:1739-46.

7. Sternberg SS, Antonelli DA, Carter D, Mills, SE, Oberman HA, editors. Diagnostic Surgical Pathology. 3rd ed. Philadelphia: Lippincott Williams \&Wilkins; 1999; 1187-1188

8. Rosai J, editor. Rosai and Ackerman's Surgical Pathology. 10th ed: St. Louis, MO: Elsevier; 2011: 1857

9. Goldblum JR, Lamps LW, McKenny J, Myers JL, editors. Rosai and Ackerman's Surgical Pathology. 11 th ed: Cambridge, MA: Elsevier; 2018 : 1674

10. Bosman FT, Carneiro F, Hruban RH, Theise ND, editors. WHO Classification of Tumours of the Digestive System, 4th ed. Lyon: International Agency for Research; 2010.

11. Wang P, Li Q, Zhang L, Ji H, Zhang CZ, Wang B. A myeloid sarcoma involving the small intestine, kidneys, mesentery, and mesenteric lymph nodes: a case report and literature review. Medicine (Baltimore). 2017;96: e7934.

12. Cicilet S, Tom FK, Philip B, Biswas A. Primary myeloid sarcoma of small bowel. BMJ Case Rep. 2017;8:2017. https://doi.org/10.1136/bcr-2017-220503.

13. Hotta K, Kunieda K. Granulocytic sarcoma of the jejunum diagnosed by biopsies during double-balloon endoscopy before treatment (with video). Dig Endosc. 2013;25:468

14. McKenna M, Arnold C, Catherwood MA, Humphreys MW, Cuthbert RJ, Bueso-Ramos C, et al. Myeloid sarcoma of the small bowel associated with a CBFbeta/MYH11 fusion and inv(16)(p13q22): a case report. J Clin Pathol. 2009;62:757-9.

15. Palanivelu C, Rangarajan M, Senthilkumar R, Annapoorni S. Laparoscopic management of an obstructing granulocytic sarcoma of the jejunum 
causing intussusception in a nonleukemic patient: report of a case. Surg Today. 2009;39:606-9.

16. Kumar B, Bommana V, Irani F, Kasmani R, Mian A, Mahajan K. An uncommon cause of small bowel obstruction: isolated primary granulocytic sarcoma. QJM. 2009;102:491-3.

17. Yoldaş T, Erol V, Demir B, Hoşcoşkun C. A rare cause of mechanical obstruction: intestinal myeloid sarcoma. Ulus Cerrahi Derg. 2013;30:176-8,

18. Kwan LY, Targan SR, Shih DQ. A case of steroid-dependent myeloid granulocytic sarcoma masquerading as Crohn's disease. World J Gastroenterol. 2011;17:2446-9.

19. Wong SW, Lai CK, Lee KF, Lai PB. Granulocytic sarcoma of the small bowel causing intestinal obstruction. Hong Kong Med J. 2005;11:204-6.

20. Ioannidis O, Cheva A, Kakoutis E, Rafail S, Kotronis A, Chatzopoulos S, et al. Primary myeloid sarcoma of the jejunum and greater omentum causing small intestine obstruction. Acta Gastroenterol Belg. 2009;72:369-72.

21. Lim SW, Lee HL, Lee KN, Jun DW, Kim IY, Kim E, et al. A case of myeloid sarcoma of intestine. Korean J Gastroenterol. 2016:68:148-51.

22. Lee SY, Park SJ, Kim YH, Lee JH. Nonleukemic granulocytic sarcoma presenting as intussusception of small bowel. Int J Clin Oncol. 2008;13:467-70.

23. Mrad K, Abid L, Driss M, Ben Abid H, Ben RK. Granulocytic sarcoma of the small intestine in a child without leukemia: report of a case with cytologic findings and immunophenotyping pitfalls. Acta Cytol. 2004;48:641-4.

24. McCusker S, Trangucci J, Frederick W, Richi AA, Abunnaja S. Primary myeloid sarcoma of the small intestine: case report and literature review. Conn Med. 2016;80:349-52.

25. Kim NR, Lee WK, Lee Jl, Cho HY. Multiple jejunal myeloid sarcomas presenting with intestinal obstruction in a non-leukemic patient: a case report with ultrastructural observations. Korean J Pathol. 2012:46:590-4.

26. Gajendra S, Gogia A, Das P, Gupta R, Tanwar P. Acute myeloid leukemia presenting as "bowel upset": a case report. J Clin Diagn Res. 2014;8:FD09-10.

27. Jung SH, Kim HC, Yu CS, Kim JC. Solitary preleukemic granulocytic sarcoma as a cause of small bowel obstruction. Gut Liver. 2007;1:82-6.

\section{Publisher's Note}

Springer Nature remains neutral with regard to jurisdictional claims in published maps and institutional affiliations.

\section{Submit your manuscript to a SpringerOpen ${ }^{\circ}$ journal and benefit from:}

- Convenient online submission

- Rigorous peer review

- Open access: articles freely available online

High visibility within the field

- Retaining the copyright to your article

Submit your next manuscript at $\boldsymbol{\nabla}$ springeropen.com 